\title{
Carbon fluxes of an alpine peatland in Northern Italy
}

\section{J.W.M. Pullens ${ }^{1,3^{*}}$, M. Sottocornola ${ }^{2}$, G. Kiely ${ }^{3}$, P. Toscana ${ }^{4}$, D. Gianelle $e^{1,5}$}

${ }^{1}$ Sustainable Agro-Ecosystems and Bioresources Department, Research and Innovation Centre - Fondazione Edmund Mach, San Michele all'Adige (TN), Italy ${ }^{2}$ Department of Chemical and Life Sciences, Waterford Institute of Technology, Waterford, Ireland

\section{Background}

Peatlands hold the largest terrestrial soil carbon pool in the world (Gorham 2008). Northern peatlands store 547 (473-621) PgC (Yu et al. 2010), which is around $20 \%$ of the total amount of the world soil organic carbon. The most studied peatlands are in high latitude region and are studied for the vulnerability of their carbon storage. Peatlands also occur in high altitude areas; for instance in the Alps there are numerous small peatland fens, which are being threatened by rising temperatures and a decrease of precipitation

\section{Objectives}

Three years of carbon fluxes of a peatland in the Italian Alps are analysed. The objectives of this study were (i) to quantify the carbon and methane fluxes and (ii) to get an insight in the carbon fluxes of alpine peatlands.

\section{Materials and methods}

Eddy covariance tower with, open and enclosed path $\mathrm{CO} 2 \mathrm{H} 2 \mathrm{O}$ analyser (LI7500 and LI7200).

Methane sensor (LI7700) applied for one year (2014)

Analysed with EddyPro 5.1.1

Gap filled with Reichstein online too

\section{Site}

10 hectares minerotrophic fen located at $1563 \mathrm{~m}$ a.s.l. on the Monte Bondone plateau, in the Italian Alps (latitude $46^{\circ} 01^{\prime} \mathrm{N}$, longitude $11^{\circ} 02^{\prime} \mathrm{E}$ ). The vegetation of the area is heterogeneous, with mainly grasses in the higher areas, Molinia caerula and Carex nigra, while in the lower areas the main vegetation consists of Carex rostrata, Scorpidium cossonii and Sphagnum spp

Long-term average precipitation (1958-2008) was 1290 $\mathrm{mm} /$ year with an average air temperature of $5.4^{\circ} \mathrm{C}$ (Eccel et al., 2012). The snow-free period typically lasts from early May to late October-November.

The runoff of the complete catchment flows on deep impermeable morainic strata.

\section{Results}

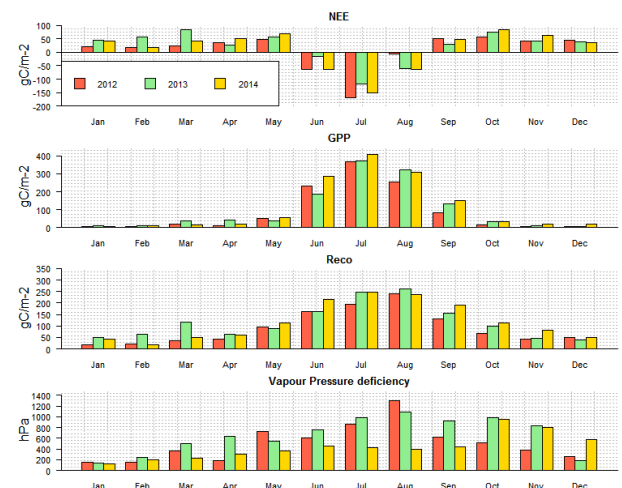

Monthly values for $\mathrm{CO}_{2}$ exchange variable across 3 years: sums of NEE, GPP, $R_{\text {eco }}$ and average vapour pressure deficiency.

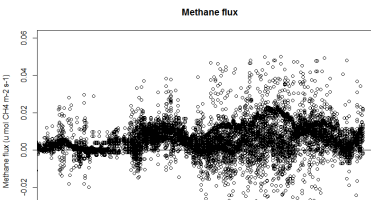

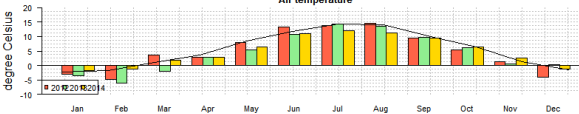
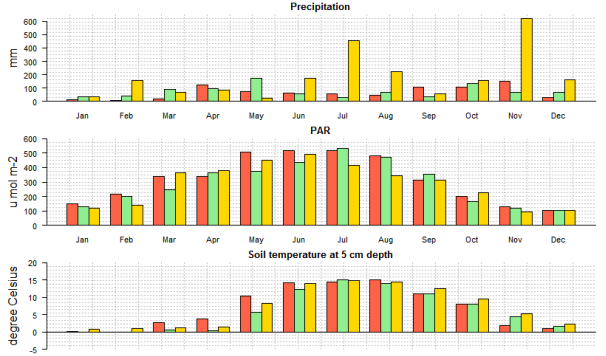

Monthly values for meteorological variables across 3 years: average air temperature with the ten-year average (Eccel et al. 2012) as a solid line, total precipitation and average photosynthetic active radiation.

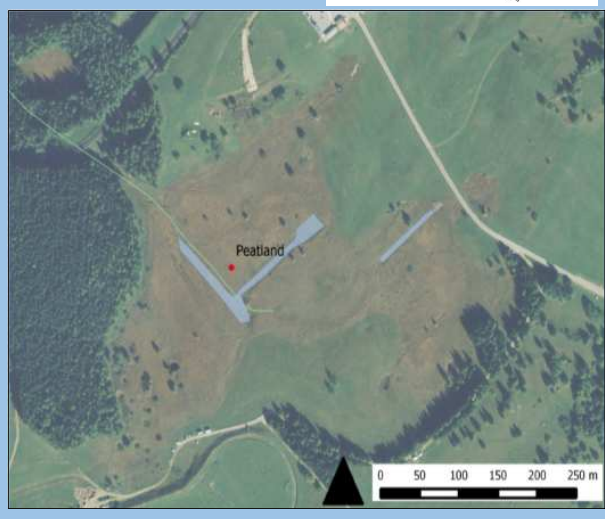

Half-hourly data points of measured $\mathrm{CH}_{4}$ fluxes.

\section{Conclusion}

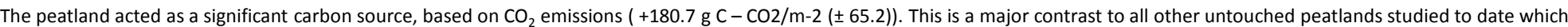
are sinks for carbon, most of which are at elevations below 300 m.a.s.l and located in the Northern hemisphere.

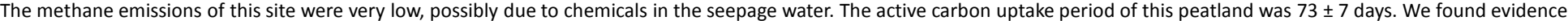
that the snow density had a big influence on the annual $\mathrm{CO}_{2}$ balance. In addition, the length of the snow-covered period was very important.

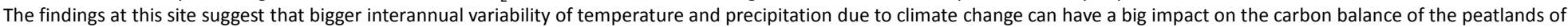
the Alp.

\section{References}

- Eccel, E., P. Cau, and R. Ranzi. 2012. Data reconstruction and homogenization for reducing uncertainties in high-resolution climate analysis in Alpine regions. Theoretical and Applied Climatology 110:345-358.

- Gorham, E. 2008. Northern Peatlands: Role in the Carbon Cycle and Probable Responses to Climatic Warming.

- Yu, Z., J. Loisel, D. P. Brosseau, D. W. Beilman, and S. J. Hunt. 2010. Global peatland dynamics since the Last Glacial Maximum. Geophysical Research Letters 37.

\section{Acknowledgement}

Travel grant is provided by the International Research School in Applied Ecology, Norway (IRSAE).

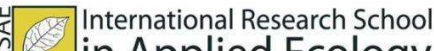

for 2012, 2013 and 2014 compared with the longterm average (1985-2008, (Eccel et al. 2012))

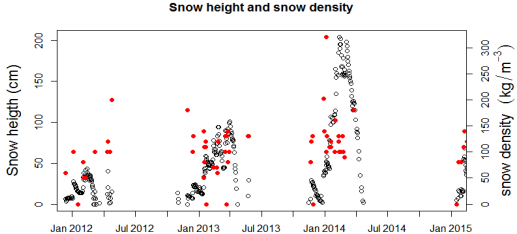

Measured snow height and snow density during the years 2012, 2013 and 2014. The snow height is depicted by the black line and the snow density by the red points. 